\title{
Antidepressant-like Effect of 1 -perillaldehyde in Stress-induced Depression-like Model Mice through Regulation of the Olfactory Nervous System
}

\author{
N. Ito, ${ }^{1}$ T. Nagai, ${ }^{1,2}$ T. Oikawa, ${ }^{1}$ H. Yamada, ${ }^{1,2}$ and T. Hanawa ${ }^{1}$ \\ ${ }^{1}$ Oriental Medicine Research Center, The Kitasato Institute, Japan \\ ${ }^{2}$ Kitasato Institute for Life Sciences and Graduate School of Infection Control Sciences, Kitasato University, Tokyo, Japan
}

Correspondence should be addressed to T. Hanawa, hanawa-t@kitasato.or.jp

Received 13 September 2007; Accepted 30 May 2008

Copyright $\odot 2011$ N. Ito et al. This is an open access article distributed under the Creative Commons Attribution License, which permits unrestricted use, distribution, and reproduction in any medium, provided the original work is properly cited.

Perillae Herba (a leaf of Perilla frutescens) has been prescribed as one of the component herbs in certain Kampo (Japanese herbal) medicines that are used clinically for the improvement of depressive mood. $l$-Perillaldehyde (PAH) is a major component in the essential oil containing in Perillae Herba, but its antidepressant-like effect has not been reported. To clarify the antidepressant-like effect of PAH, the inhaled effect of PAH on stress-induced depression-like model mice prepared by subjection to a combination of forced swimming and chronic mild stresses was investigated. The degree of the depression-like state was measured by the animal's duration of immobility using a forced swimming test. Inhalation of PAH ( 0.0965 and $0.965 \mathrm{mg} / \mathrm{mouse} /$ day, 9 days $)$ significantly shortened the duration of immobility of the depression-like model mice and did not affect locomotor activity. However, another odor substance, cinnamaldehyde containing in Cinnamomi Cortex, exhibited no reduction in the immobility. The reduction in the immobility induced by the inhalation of PAH was prevented on anosmia-induced mice prepared by intranasal irrigation with zinc sulfate. These results suggest that the inhalation of PAH shows antidepressant-like activity through the olfactory nervous function.

\section{Introduction}

Depression is a long-lasting mental disorder, and the prevalence for lifetime estimates with the majority in the range of $8-12 \%$ in 10 countries in Europe, the U.S. and Asia [1]. Patients with depression are often prescribed antidepressants, but antidepressants have adverse effects such as dysuria, digestive dysfunction and sexual dysfunction. Therefore, safer and more effective treatments for depression are needed.

In an animal model using a forced swimming test (FST), it was reported that the odor of lemon has an antidepressantlike property [2]. This finding suggests that the sensory action via the olfactory nervous system might be associated with the antidepressant-like effect. Therefore, it is expected that treatments for depression using odor inhalation will be developed. When patients themselves decoct and take Kampo (Japanese herbal) medicines, they can inhale the odor of the decoction, indicating that pharmacological effects of the odor via the olfactory nervous system may be expected.
Perillae Herba is prescribed as one of the component herbs of such Kampo medicines as kososan (Xiang-Su-San in Chinese) and hangekobokuto (Banxia-Houpo-Tang in Chinese), which are used clinically for the improvement of depressive mood and in which antidepressant-like activities have been reported experimentally $[3,4]$. It has also been reported that the administration of rosmarinic acid or caffeic acid containing in Perillae Herba exhibited antidepressantlike activities in an animal model of depression [5]. However, the antidepressant-like effect of $l$-perillaldehyde (PAH), which is a major component of essential oil containing in Perillae Herba, has not been reported.

The present study investigated whether the inhalation of $\mathrm{PAH}$ shows an antidepressant-like activity by using stressinduced depression-like model mice. The antidepressant-like activity of PAH through the olfactory nervous system was also studied by using anosmia-induced model mice.

\section{Materials and Methods}

2.1. Animals. Seven-week-old male ddY mice (Japan SLC, Hamamatsu, Japan), weighing 35-40 g, were used. The mice 
<smiles>C=C(C)[C@H]1CC=C(C=O)CC1</smiles>

Figure 1: Structure of $l$-perillaldehyde (PAH).

were housed under conditions of constant temperature $(23 \pm$ $2^{\circ} \mathrm{C}$ ), humidity $(55 \pm 10 \%)$ and a $12 \mathrm{~h}$ light cycle (lights on at 8:00) with food and water available ad libitum. All animal experiments were performed according to the Guide for Care and Use of Laboratory Animals at The Kitasato Institute and Kitasato University.

2.2. Drugs and Reagents. l-Perillaldehyde (PAH; Figure 1) (Aldrich Chemical Co. Ltd., St. Louis, MO) was diluted in $0.1,1.0$ and $10 \%(\mathrm{v} / \mathrm{v})$ with ethanol, and cinnamaldehyde (CAH) (Wako Pure Chemical Industries, Osaka, Japan) was also diluted in $10 \%(\mathrm{v} / \mathrm{v})$ with ethanol. Toledomin ${ }^{\circledR}$ (milnacipran hydrochloride) (Asahi Kasei Pharma Corp., Tokyo, Japan) was suspended in distilled water. $\mathrm{ZnSO}_{4}$ (Wako) was dissolved in 5\% (w/v) with saline. Isovaleric acid (Wako) was diluted in $1 \%(\mathrm{v} / \mathrm{v})$ with water.

2.3. Drug Treatment. The mice were made to inhale $\mathrm{PAH}$ $(0.1,1.0$ and $10 \%)$ or CAH (10\%) by dropping the solution on an area between the nose and eyes in a volume of $10 \mu \mathrm{l} /$ mouse once daily at days $1,2,4,5,6,7,8,9$ and 11 (9 times) (Scheme 1(a)). Milnacipran hydrochloride (MIL) $(60 \mathrm{mg} / \mathrm{kg})$ was administered orally to the mice by intragastric gavage in a volume of $0.5 \mathrm{ml} /$ mouse once daily at days $1,2,4,5,6,7,8,9$ and 11 (9 times).

2.4. Stress-Induced Depression-Like Model Mice. The stressinduced depression-like model mice [3] were prepared by a combination of modified forced swimming (FS) twice with 11-day interval $[6,7]$ and chronic mild stress (CMS) $[8,9]$. Briefly, the mice were individually placed into 51 glass beakers (height $27 \mathrm{~cm}$, diameter $18 \mathrm{~cm}$ ) filled with 4 of water $\left(23 \pm 1^{\circ} \mathrm{C}\right)$ for $15 \mathrm{~min}$. The beakers were separated by non-transparent panels to prevent the mice from seeing each other. After $15 \mathrm{~min}$ in the water, the mice were removed and allowed to dry with a drier before being returned to their home cages. The mice were then separated into groups by measuring the duration of immobilities for the first $5 \mathrm{~min}$ of FS to minimize the variability of immobility among the groups. A mouse was judged to be immobile when it ceased struggling and remained floating motionless in the water, making only those movements necessary to keep its head above water. After 2 days, the mice were exposed to CMS,

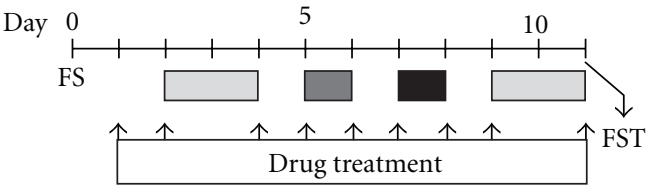

(a)

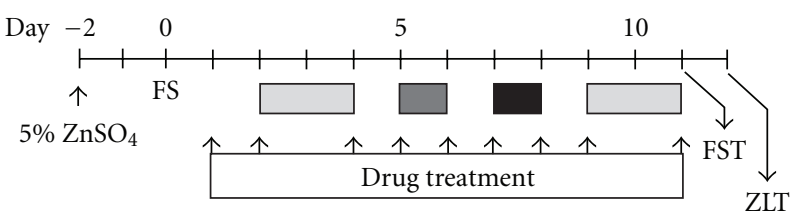

CMS 1

$\square$ CMS 2

CMS 3

(b)

Scheme 1: Schedule for the drug treatment on stress-induced depression-like model mice (a) and preparation of anosmiainduced mice (b). (a) Briefly, mice were individually placed into water for $15 \mathrm{~min}$ (forced swimming; FS). After 2 days, the mice were exposed to chronic mild stress (CMS 1, CMS 2 and CMS 3), which consisted of three different stress situations. The mice were then placed again into water at $60 \mathrm{~min}$ after the final treatment of the drug, and the total duration of immobility during a $5 \mathrm{~min}$ forced swimming test (FST) was measured. Drugs were treated at days 1 , 2, 4, 5, 6, 7, 8, 9 and 11 (9 times). (b) Briefly, intranasal irrigation with $20 \mu \mathrm{l}$ of $5 \% \mathrm{ZnSO}_{4}$ was performed slowly into the bilateral nose under light anesthesia 2 days before FS. After exposure to stresses (mentioned above), the total duration of immobility during a $5 \mathrm{~min}$ FST was measured. Following day, the time which the mice spent on the $1 \%$ isovaleric acid side was measured for $5 \mathrm{~min}$ in the $\mathrm{ZnSO}_{4}$ lesioned test (ZLT). Drugs were treated as same schedule as above (9 times).

which consisted of three different stress situations: tilting of the cage twice 30 degrees from the horizontal (CMS 1), pouring $200 \mathrm{ml}$ of water onto the sawdust bedding of the cage (CMS 2) and shaking the cages at $200 \mathrm{rpm}$ by a Green S. Seriker II (Vision Scientific, Kyunggi, Korea) (CMS 3). These stress situations were applied for 48,24 and $24 \mathrm{~h}$, respectively, with $24 \mathrm{~h}$ intervals (Scheme 1). The mice were then placed again into water at $60 \mathrm{~min}$ after the final treatment of the drug, and the total duration of immobility during a $5 \mathrm{~min}$ FST was measured.

2.5. Spontaneous Locomotor Activity Test. The spontaneous locomotor activities of the mice were evaluated by the open field test. Briefly, the mice were individually placed in the center of an open field $(40 \times 40 \times 20 \mathrm{~cm})$ with the field divided into 25 equal squares (Sanki Kagaku Kogei, Kawasaki, Japan) and allowed to move freely for $15 \mathrm{~min}$. The total number of line crosses for the first 5 min were counted to minimize the variability of the total number of line crosses among the groups. Eleven days later, the mice were again individually placed in the open field and the total numbers 
of line crosses were counted during a $5 \mathrm{~min}$ interval $60 \mathrm{~min}$ after the final drug treatment.

2.6. Anosmia-Induced Mice. Anosmia was induced according to the modified method of Alberts and Galef [10]. Briefly, intranasal irrigation with $20 \mu \mathrm{l}$ of $5 \% \mathrm{ZnSO}_{4}$ was performed slowly into the bilateral nose under light anesthesia with Nembutal (Dainippon Pharmaceutical Co., Ltd, Osaka, Japan) 2 days before FS. The control mice were intranasally perfused with saline (Scheme 1(b)).

2.7. $\mathrm{ZnSO}_{4}$-Lesioned Test (ZLT). The degree of anosmia was evaluated by a behavior of escape from a bad smell [11]. Briefly, the mice were individually placed into the center of an emptied cage in which a center line had been drawn. Kimwipe soaked in 1\% isovaleric acid solution, which is a bad smell essence, was placed on one side of the line, and kimwipe soaking water on the other side. One day after FST, the time which the mice spent on the $1 \%$ isovaleric acid side was measured for $5 \mathrm{~min}$ (Scheme 1(b)). If anosmia had been induced in the mice, which meant they showed a low perception of odor, the latency of the $1 \%$ isovaleric acid side of the mice was longer than that of the control mice.

2.8. Statistical Analysis. All data were expressed as the mean \pm standard error of the mean (SEM). Results were analysed by one-way analysis of variance (ANOVA). Post hoc comparisons, if applicable, were carried out using Fisher's PLSD, Dunnett's or Tukey's tests. $P$-values less than $.05(P$ $<.05)$ were considered indicative of significance.

\section{Results}

3.1. Inhalation of PAH, but Not CAH, Reduces the Immobility of Stress-Induced Depression-Like Model Mice in the FST. Sixty minutes after the last inhalation, $\mathrm{PAH}$ ( 0.0965 and $0.965 \mathrm{mg} / \mathrm{mouse} /$ day) significantly reduced the duration of immobility in a dose-dependent manner as compared with the vehicle-treated mice $(P<.05$ and $P<.01$, resp.) (Figure $2(\mathrm{a}))$. However, the inhalation of $\mathrm{CAH}(1.05 \mathrm{mg} / \mathrm{mouse} /$ day $)$ did not reduce the duration of immobility as compared with the vehicle-treated mice (Figure 2(b)).

3.2. Inhalation of PAH Does Not Affect the Spontaneous Locomotor Activity of Mice. Sixty minutes after the last inhalation, PAH $(0.00965,0.0965$ and $0.965 \mathrm{mg} / \mathrm{mouse} /$ day $)$ did not change the total counts $(177.6 \pm 23.6,165.8 \pm$ 19.2 and $190.4 \pm 19.5$, resp.) of line crosses for $5 \mathrm{~min}$ as compared with the vehicle-treated mice $(173.5 \pm 31.9)$ (data not shown).

3.3. Behavioral Verification of Anosmia-Induced Mice. The latency of the $\mathrm{ZnSO}_{4}$-treated mice on the $1 \%$ isovaleric acid side was significantly increased compared with the salinetreated mice under the stress-free condition $(P<.01)$; however, the latency of the $\mathrm{ZnSO}_{4}$-treated mice was not changed under the stress condition compared with the stress-free

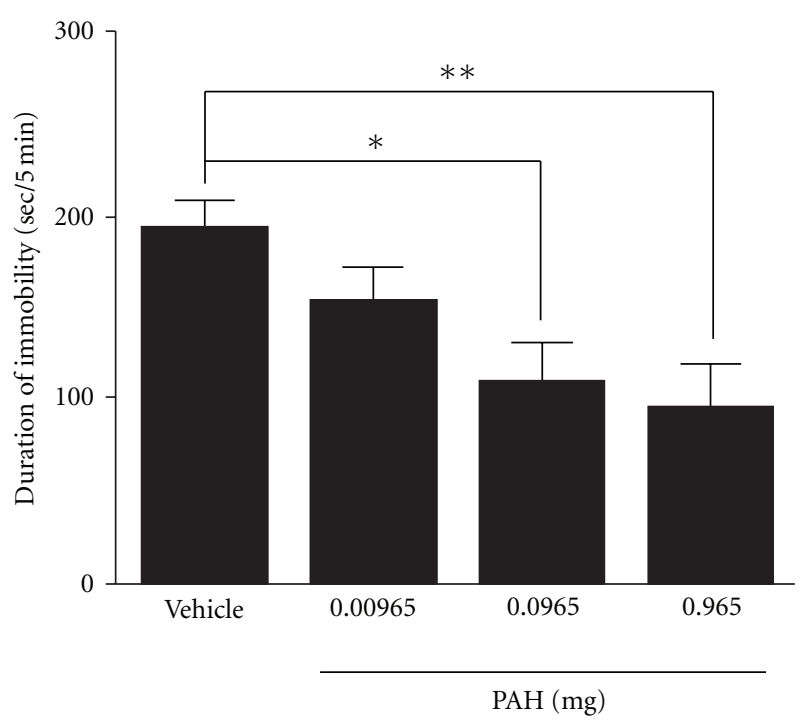

(a)

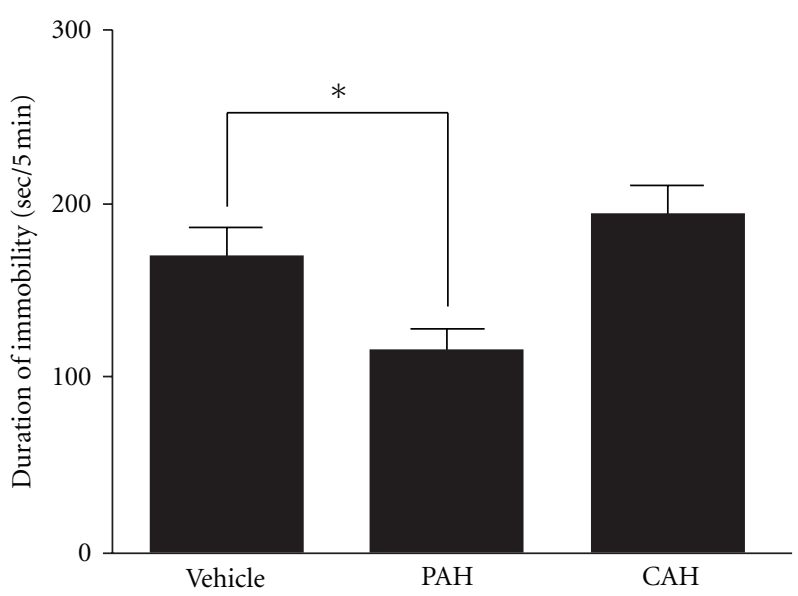

(b)

FIgURE 2: Effects of the inhalation of PAH and/or CAH on the duration of immobility of stress-induced depression-like model mice in the FST. (a) After treatments of PAH $(0.00965,0.0965$ and $0.965 \mathrm{mg}$ ) for 9 days, the duration of immobility was measured. (b) After treatments of PAH (0.965 mg) and CAH (1.05 mg) for 9 days, the duration of immobility was measured. Each column represents the mean \pm SEM of $8-10$ mice per group. ${ }^{*} P<.05$ and ${ }^{* *} P<.01$ with Dunnett's test (a) or Fisher's PLSD test (b). CAH, cinnamaldehyde.

condition (Figure 3(a)). The duration of immobility of the $\mathrm{ZnSO}_{4}$-treated mice in the FST was significantly increased under the stress condition compared with the stress-free condition; however, the duration of immobility under the stress condition was not changed in the $\mathrm{ZnSO}_{4}$-treated mice compared with the saline-treated mice (Figure 3(b)). Moreover, the increase of immobility under the stress condition was shortened by oral administration of an antidepressant, MIL, in the $\mathrm{ZnSO}_{4}$-treated mice (data not shown). 


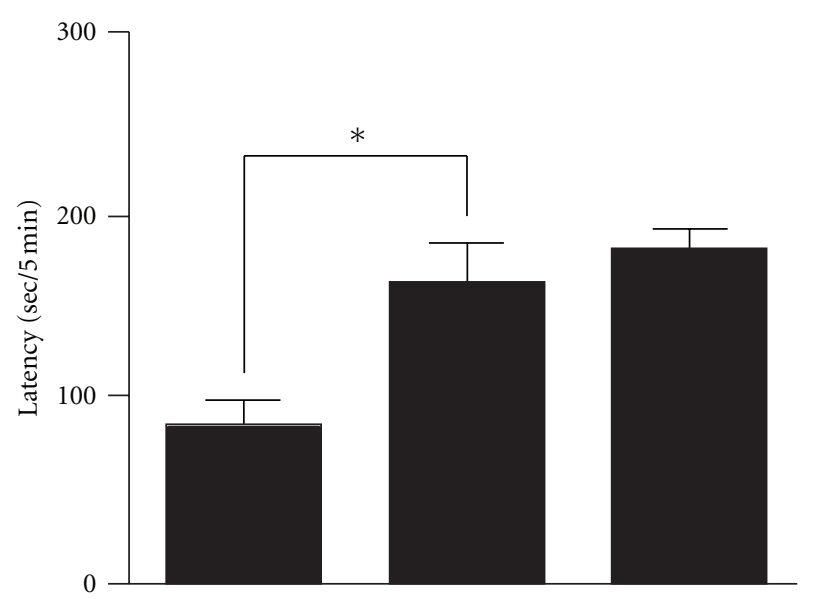

(a)

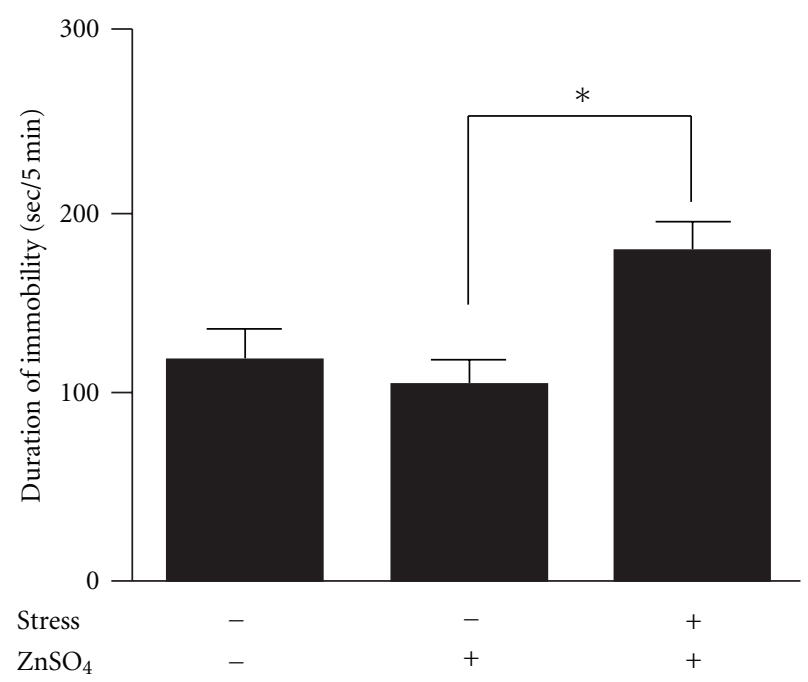

(b)

FIGURE 3: Influences of $\mathrm{ZnSO}_{4}$ on the latency of $1 \%$ isovaleric acid side in the ZLT (a) and the duration of immobility of stress-induced depression-like model mice in the FST (b). Each column represents the mean \pm SEM of $10-11$ mice per group. ${ }^{*} P<.01$ with Fisher's PLSD test. ZLT, $\mathrm{ZnSO}_{4}$-lesioned test.

3.4. Reduction of Immobility due to Inhalation of PAH Is Blocked in Anosmia-Induced Mice. Under the stress condition, the reduction of immobility by the treatment of PAH $(0.965 \mathrm{mg} / \mathrm{mouse} /$ day $)$ was significantly prevented in the anosmia-induced mice $(P<.01$; Figure 4$)$.

\section{Discussion}

In the present study, we have shown that the inhalation of PAH containing in Perillae Herba showed an antidepressantlike effect in the stress-induced depression-like model mice, and that its effect was exhibited via the olfactory nervous system.

It is considered difficult to design inhaled doses of PAH both because inhaled drugs are not directly administered into

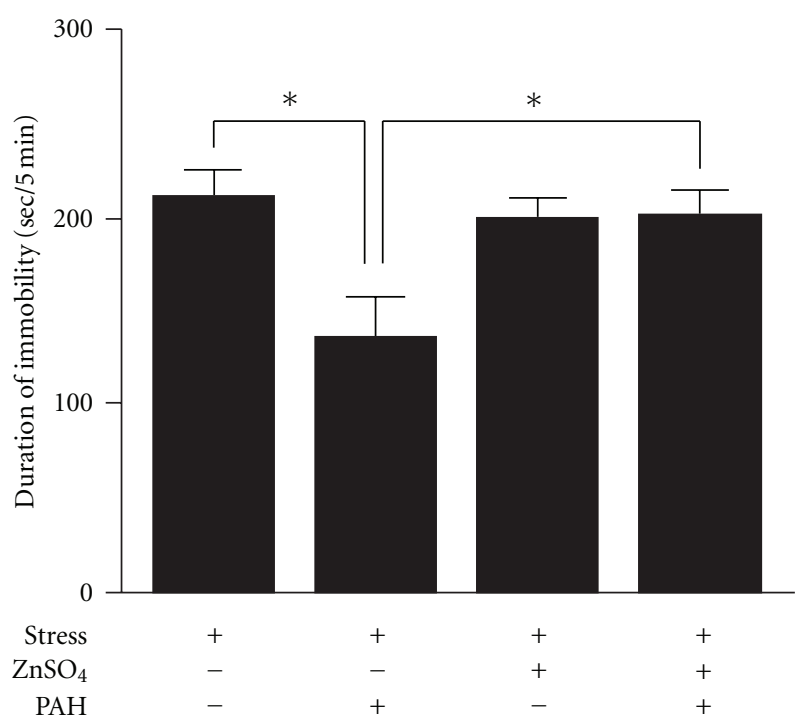

Figure 4: Effects of PAH on the duration of immobility in the FST against anosmia-induced depression-like model mice. After treatments of PAH $(0.965 \mathrm{mg})$ for 9 days, the duration of immobility was measured. Each column represents the mean \pm SEM of $10-11$ mice per group. ${ }^{*} P<.01$ with Tukey's test.

the body and because the sensitivity of the olfactory nervous system varies between humans and rodents. In our study, $\mathrm{PAH}$ was inhaled at a dose which was approximately 1.3130 times lower than the concentration of PAH containing in the water-extract of Perillae Herba ( $2 \mathrm{~g})$ in kososan, which is used clinically as a one day dosage [12], because rodents have more sensitive olfaction than humans. The inhalation of PAH reduced the immobility in a dose-dependent manner (Figure 2(a)), and did not affect spontaneous locomotor activity (data not shown), indicating that the inhalation of PAH shows an antidepressant-like property. However, CAH, which is a major component of the essential oil containing in Cinnamomi Cortex, did not reduce the immobility in the present study (Figure 2(b)), and it has also been reported that essential oils such as jasmine, ylang-ylang, clove, sandalwood, peppermint, lavender, rose, camphor and pine have no effects on immobility [2]. These results suggest that not all essential oils have an antidepressant-like effect. In the present study, we demonstrated the unprecedented treatment of $\mathrm{PAH}$ by dropping it on an area between the nose and eyes in mice. The advantages of this treatment are that each mouse can inhale a constant dose of essential oil, and the mice are not exposed excessively to additional stress against a novel environment, as they are in the method of inhalation in which an apparatus is used for essential oil application [2]. Conversely, since the essential oil was directly dropped onto the area between the nose and eyes, the possibility that the cutaneous absorption of PAH contributed to its antidepressant-like effect cannot be excluded. Therefore, we investigated whether the antidepressant-like effect of $\mathrm{PAH}$ is blocked in the mice lesioned olfactory nervous system with the intranasal irrigation of $\mathrm{ZnSO}_{4}$. When the degree of anosmia by the treatment of $\mathrm{ZnSO}_{4}$ was verified in 
the behavioral experiment, the $\mathrm{ZnSO}_{4}$-treated mice had a significant disruption of the olfactory nervous function (Figure 3(a)). Moreover, histological lesion of the olfactory nervous system was also observed in the $\mathrm{ZnSO}_{4}$-treated mice by immunohistochemical study (data not shown). Several studies have reported that many characteristic depressive behaviors (disrupted circadian patterns in sleep and feeding; increased irritability and hyperactivity responses to a novel, stressful environment) observed in olfactory-bulbectomized animals are not detected in $\mathrm{ZnSO}_{4}$-treated mice [13-15]. In the present study, the immobility of the $\mathrm{ZnSO}_{4}$-treated mice in the FST was not different from that of the vehicle-treated mice (Figure 3(b)). Moreover, the oral administration of MIL (serotonin-noradrenaline reuptake inhibitor) significantly exhibited the reduction of immobility compared with the vehicle-treated mice in the anosmia-induced mice (data not shown). These results indicate that mice in which anosmia is induced by $\mathrm{ZnSO}_{4}$ can be used to test behavioral pharmacological strategies for depression. The reduction of immobility induced by the inhalation of PAH in olfactory-unlesioned depression-like model mice was blocked in the anosmiainduced mice. These results suggest that the inhalation of $\mathrm{PAH}$ exhibits an antidepressant-like effect via the olfactory nervous system, but not via cutaneous absorption.

The oral administration of $\mathrm{PAH}$ also exhibited an antidepressant-like effect in the depression-like model mice, although its effective doses of PAH (24 and $120 \mathrm{mg} \mathrm{kg}^{-1}$ ) were very high compared with those for the inhaled study (data not shown). Although it has been reported that the oral administration of PAH acted on the central nervous system [13], the antidepressant-like activity of PAH has never been reported. This study represents the first report showing the antidepressant-like effect of PAH inhalation. In the present study, it is not, however, known whether PAH in the Perillae Herba contributes to the antidepressantlike activity of Kampo medicines such as kososan and hangekobokuto containing Perillae Herba as one of the component herbs. From the report that citrus fragrance contributes to the reduction of doses of antidepressants in an animal experiment [2], the combination of antidepressants and odors may be useful for exhibiting the antidepressant effects in a synergistic manner. Our finding, as well as the report that the odor of lemon exhibits an antidepressantlike effect [2], together present scientific evidence of the antidepressant-like effect of the odor.

Further investigation of the mechanism of PAH on the antidepressant-like effect is now in progress.

\section{Acknowledgment}

The authors would like to thank Ms. N. Sakurada for her technical assistance.

\section{References}

[1] L. Andrade, J. J. Caraveo-Anduaga, P. Berglund, R. V. Bijl, R. De Graaf, and W. Vollebergh, "The epidemiology of major depressive episodes: results from the International Consortium of Psychiatric Epidemiology (ICPE) Surveys,"
International Journal of Methods in Psychiatric Research, vol. 12, pp. 3-21, 2003.

[2] T. Komori, R. Fujiwara, M. Tanida, and J. Nomura, "Potential antidepressant effects of lemon odor in rats," European Neuropsychopharmacology, vol. 5, no. 4, pp. 477-480, 1995.

[3] N. Ito, T. Nagai, T. Yabe, S. Nunome, T. Hanawa, and H. Yamada, "Antidepressant-like activity of a Kampo (Japanese herbal) medicine, Koso-san (Xiang-Su-San), and its mode of action via the hypothalamic-pituitary-adrenal axis," Phytomedicine, vol. 13, no. 9-10, pp. 658-667, 2006.

[4] L. Luo, J. Nong Wang, L. D. Kong, Q. G. Jiang, and R. X. Tan, "Antidepressant effects of Banxia Houpu decoction, a traditional Chinese medicinal empirical formula," Journal of Ethnopharmacology, vol. 73, no. 1-2, pp. 277-281, 2000.

[5] H. Takeda, M. Tsuji, M. Inazu, T. Egashira, and T. Matsumiya, "Rosmarinic acid and caffeic acid produce antidepressive-like effect in the forced swimming test in mice," European Journal of Pharmacology, vol. 449, no. 3, pp. 261-267, 2002.

[6] M. J. Detke, J. Johnson, and I. Lucki, "Acute and chronic antidepressant drug treatment in the rat forced swimming test model of depression," Experimental and Clinical Psychopharmacology, vol. 5, no. 2, pp. 107-112, 1997.

[7] R. D. Porsolt, A. Bertin, and M. Jalfre, "Behavioral despair in mice: a primary screening test for antidepressants," Archives Internationales de Pharmacodynamie et de Therapie, vol. 229, no. 2, pp. 327-336, 1977.

[8] L. C. Solberg, T. H. Horton, and F. W. Turek, "Circadian rhythms and depression: effects of exercise in an animal model," American Journal of Physiology, vol. 276, no. 1, pp. R152-R161, 1999.

[9] P. Willner, A. Towell, D. Sampson, S. Sophokleous, and R. Muscat, "Reduction of sucrose preference by chronic unpredictable mild stress, and its restoration by a tricyclic antidepressant," Psychopharmacology, vol. 93, no. 3, pp. 358364, 1987.

[10] J. R. Alberts and B. G. Galef Jr., "Acute anosmia in the rat: a behavioral test of a peripherally-induced olfactory deficit," Physiology and Behavior, vol. 6, no. 5, pp. 619-621, 1971.

[11] N. Mikuriya, Y. Kim, and K. Fujimura, "The effect of the aroma of patchouli essential oil on defecation and constipation," Aroma Research, vol. 5, pp. 70-75, 2004.

[12] A. Sugaya, T. Tsuda, and T. Obuchi, "Pharmacological studies on Perillae Herba. I. Neuropharmacological action of water extract and perillaldehyde," Yakugaku Zasshi, vol. 101, pp. 642-648, 1981 (Japanese).

[13] J. R. Alberts and M. I. Friedman, "Olfactory bulb removal but not anosmia increases emotionality and mouse killing," Nature, vol. 238, no. 5365, pp. 454-455, 1972.

[14] D. A. Edwards, "Non sensory involvement of the olfactory bulbs in the mediation of social behaviors," Behavioral Biology, vol. 11, no. 3, pp. 287-302, 1974.

[15] M. H. Sieck and H. D. Baumbach, "Differential effects of peripheral and central anosmia producing techniques on spontaneous behavior patterns," Physiology and Behavior, vol. 13, no. 3, pp. 407-425, 1974. 


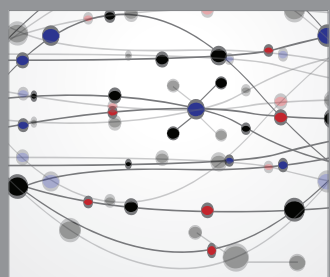

The Scientific World Journal
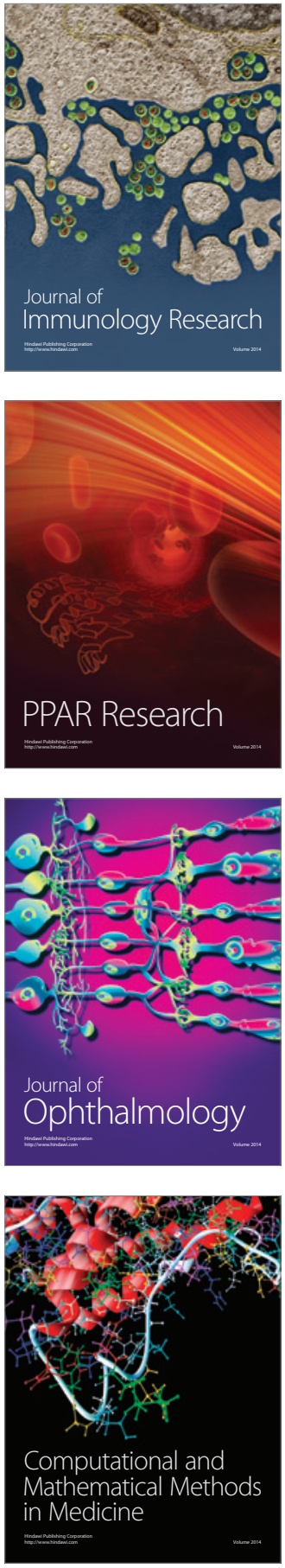

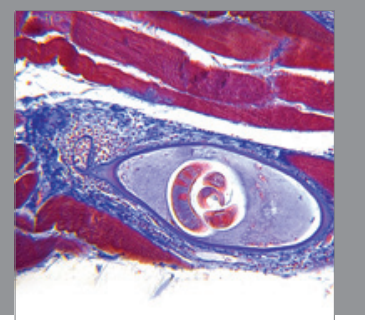

Gastroenterology

Research and Practice
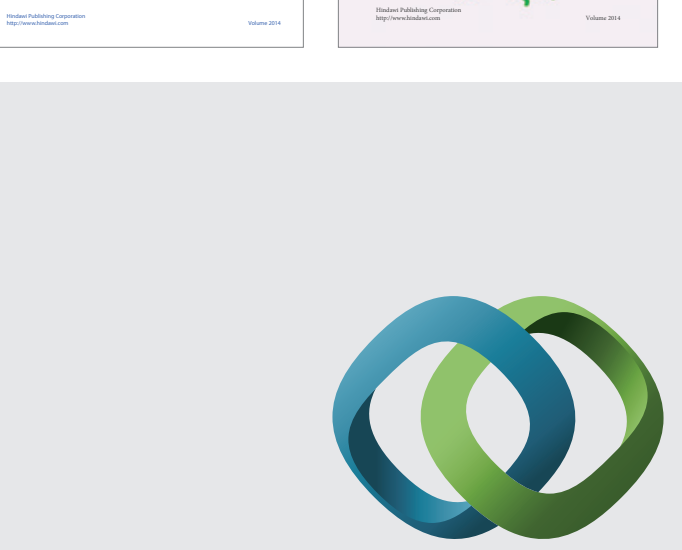

\section{Hindawi}

Submit your manuscripts at

http://www.hindawi.com
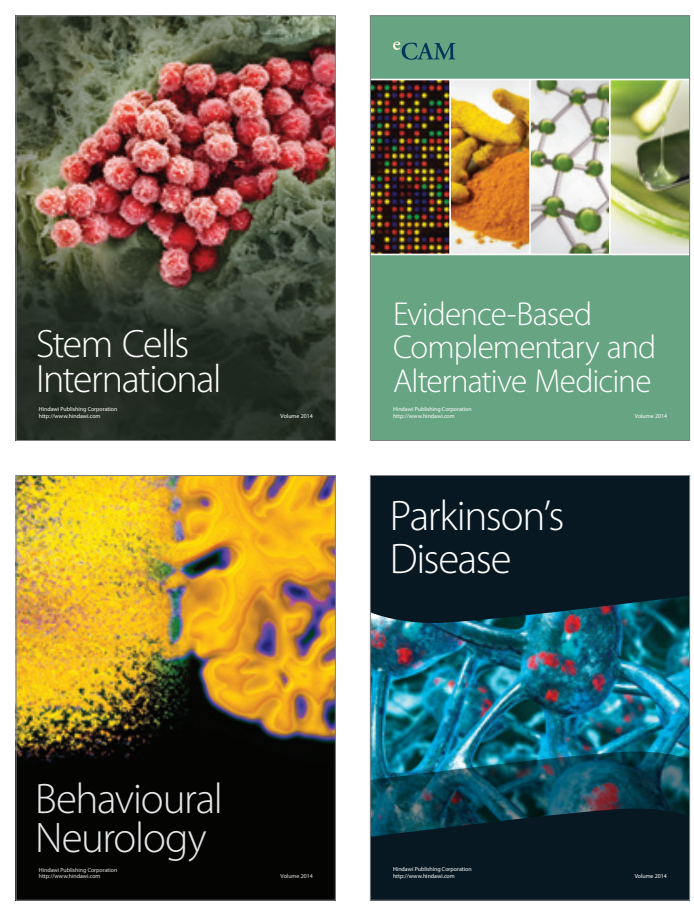

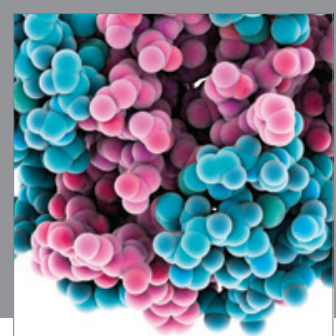

Journal of
Diabetes Research

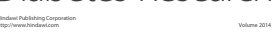

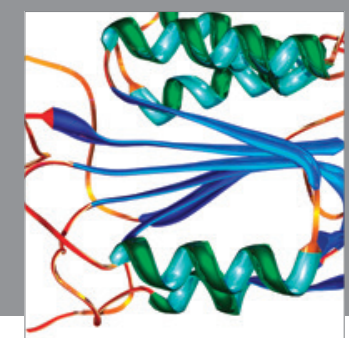

Disease Markers
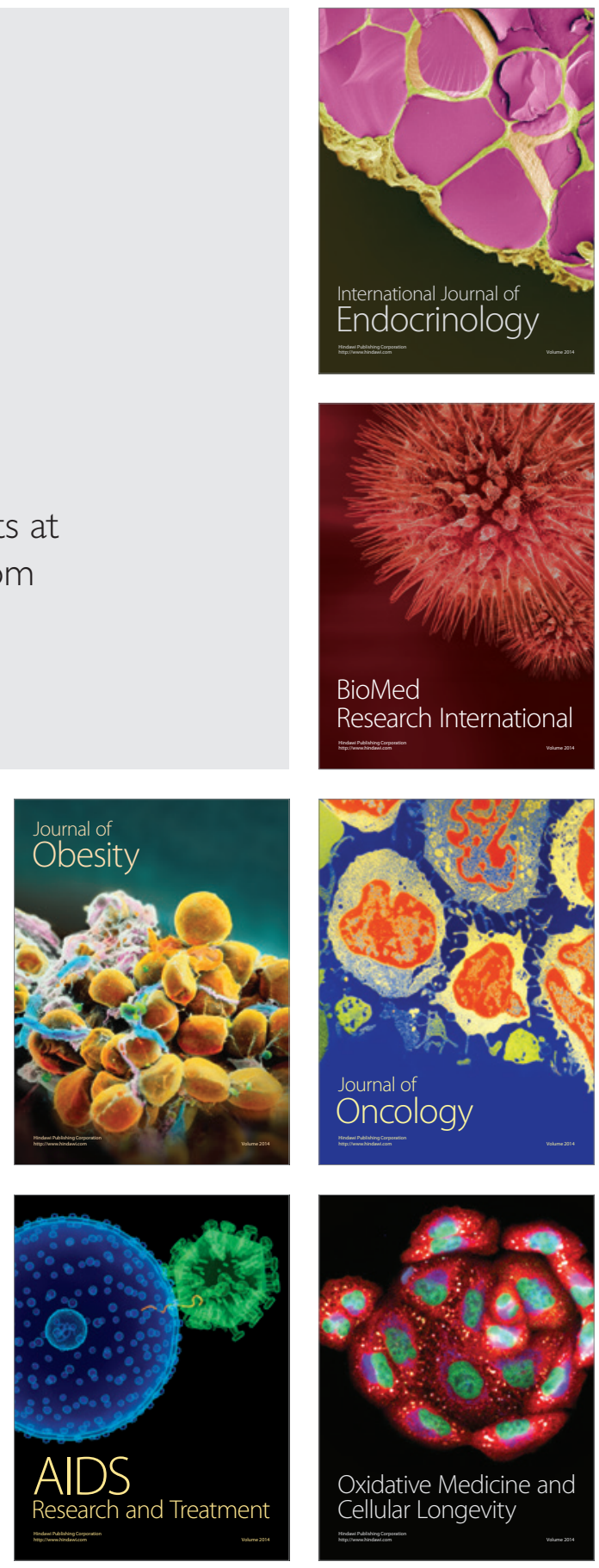